\title{
HALAL HARAM DALAM PERSPEKTIF PENDIDIKAN (Kajian Hadis Tahlili)
}

\author{
Risna Mosiba \\ Fakultas Ushuluddin, Filsafat dan Politik \\ Universitas Islam Negeri Alauddin Makassar \\ Email: risnasayang77@yahoo.com
}

\begin{abstract}
Rasulullah saw. educate the people well, by making various parables and explaining them. We can understand this from various traditions. In Islamic law, halal and haram issues are very clear. While the vague is only known by some people about the law and its arguments. When a case is not clear to humans, whether halal or haram, then it should be avoided until it becomes clear to him that the case is halal or haram. Be careful (and keep away) from the shubhat matters is an effort to guard one's self over his religious faith and guard against his pride from reproaches. In fact, someone, if he falls into the matter of syubhat, he will easily underestimate matters that are clearly the law of his prohibition.
\end{abstract}

Keywords: Hadith, Halal and Haram, Educate

\section{PENDAHULUAN}

\section{A. Latar Belakang}

etenangan hidup di dunia adalah dambaan setiap orang akan tetapi banyak
manusia yang hidupnya penuh dengan kegelisahan, ketakutan dan kecemasan. hidup di tengah-tengah manusia dalam keadaan dicintai Allah dan dicintai manusia.

Merupakan prinsip dasar Islam, bahwa seorang muslim wajib mengikatkan perbuatannya dengan hukum syara', sebagai konsekuensi keimanannya pada Islam. Sabda Rasulullah saw., "Tidak sempurna iman salah seorang dari kamu, hingga hawa nafsunya mengikuti apa yang aku bawa (Islam)"

Maka sudah seharusnya seorang muslim mengetahui perkara-perkara yang dilakukannya. Asas kepada sesuatu perkara di dalam Islam itu tidak terlepas kepada lima perkara yaitu: halal, haram, sunat, wajib dan makruh. Mencari sesuatu yang halal itu adalah wajib bagi umat Islam sebagaimana sabda Rasulullah saw. yang berbunyi:

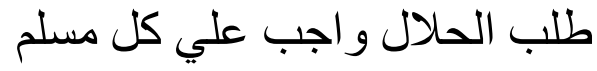

Terjemahnya:

"Mencari yang halal adalah suatu kewajiban bagi setiap muslim". (HR. alTabrani)

Bagi perkara halal secara mutlak kita dituntut untuk mencarinya, begitu juga 
perkara haram kita dituntut untuk meninggalkannya, sementara perkara syubhat pula amat perlu untuk dijauhi.

\section{B. Rumusan Masalah}

Berdasar pada uraian latar belakang yang telah dipaparkan, maka dapat dirumuskan masalah dalam makalah ini sebagai berikut:

1. Bagaimana redaksi serta kualitas hadis tentang halal dan haram?

2. Bagaimana syarah tahlili hadis tersebut?

3. Pelajaran apa yang terkandung dalam hadis tersebut?

Sesuai dengan rumusan masalah di atas, maka pembahasan ini akan mengkaji dua kitab syarah hadis sekaligus, yang secara metodologis pem-bahasannya disebut sebagai dirāsat al-muqāranah (kajian perbandingan).

\section{Metode Kajian yang digunakan}

Di kalangan para pengkaji Alquran, secara metodologis tafsir dikenal dengan empat metode yakni tahlīliy, ${ }^{1}$ ijmāliy, ${ }^{2}$ muqāran ${ }^{3}$ dan mawdhū'iy. ${ }^{4}$ Sementara teknik

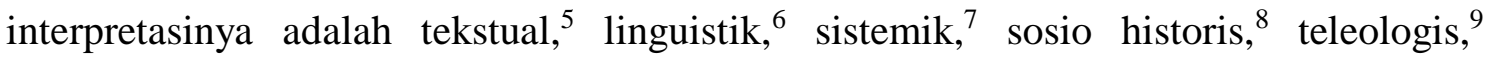
kultural, ${ }^{10}$ logis ${ }^{11}$ dan interpretasi ganda. ${ }^{12}$

${ }^{1}$ Metode tafsīr tahlīliy adalah suatu metode tafsir yang bermaksud menjelaskan kandungan ayatayat Alquran dari seluruh aspeknya dengan memperhatikan runtut ayat-ayat Alquran sebagaimana yang tercantum dalam mushaf, bermula dari arti kosa kata, asbāb al-Nuzūl, munāsabah, syarh ayat dan selainnya. Lihat Abd. al-Hayy al-Farmāwy, al-Bidāyat fi al-tafsīr al-Mawdū'iy, diterjemahkan oleh Siryan A. Jamrah dengan judul Metode Tafsir Mawdhu'iy (Cet. I; Jakarta: LSIK dan PT. Raja Grafindo Persada, 1994), h. 12

${ }^{2}$ Metode tafsìr ijmāliy adalah suatu metode tafsir yang menafsirkan ayat-ayat Alquran dengan cara mengemukakan makna-makna global. Dalam sistematikan uraiannya, penafsir membahas ayat-ayat demi ayat sesuai dengan susunan yang ada dalam mushaf. Lihat ibid., h. 29

3 Metode tafsìr muqāran adalah suatu metode tafsir yang mengemukakan penasiran ayat-ayat Alquran yang ditulis oleh sejumlah mufassir, kemudian ia membandingkan arah dan kecenderungan masing-masing mufassir. Lihat, ibid., h. 30

${ }^{4}$ Tafsìr bi al-Mawdü'iy adalah suatu metode tafsir yang menghimpun ayat-ayat Alquran yang mempunyai maksud sama dalam arti sama-sama membicarakan satu topik masalah dan menyusunnya berdasarkan kronologi serta sebab turunnya ayat-ayat tersebut. Lihat ibid., h. 36.

5 Teknik interpretasi tekstual, yakni ayat-ayat Alquran yang diteliti ditafsirkan dengan menggunakan teks-teks Alquran sendiri ataupun hadis Nabi. Uraian lebih lanjut, lihat H. Abd. Muin Salim, Fiqh Siyasah; Konsepsi Kekuasaan Politik dalam Al-Quran (Cet. I; Jakarta: RajaGrafindo Persada, 1994), h. 33

${ }^{6}$ Teknik interpretasi linguistik, yakni ayat-ayat Alquran ditafsirkan dengan meng-gunakan kaedahkaedah kebahasaan. Teknik ini mencakup interpretasi dalam bidang semantik etimologis, semantik morfologis, semantik leksikal, semantik gramatikal dan semantik retorikal. Ibid., h. 34

7 Teknik interpretasi sistemik, yakni ayat-ayat Alquran ditafsirkan berdasarkan analisis dengan melihat perpautannya dengan dengan ayat-ayat atau bagian-bagian lainnya yang ada disekitarnya. Ibid.

8 Teknik iterpretasi sosio historis, yakni ayat-ayat Alquran ditafsirkan dengan meng-unakan riwayat mengenai kehidupan sosial politik dan kultural bangsa Arab pada saat diturunkan Alquran. Dengan kata lain ayat ditafsirkan dengan menggunakan sebab turunnya ayat. Ibid., h. 35 
Jika para mufassir dalam menafsirkan ayat-ayat Alquran, tidak terlepas dari penggunaan berbagai metode tafsir dan teknik interpretasi yang telah disebutkan di atas, maka para muhaddis dalam hal ini para pen-syarah hadis juga tidak terlepas dengan penggunaan multi metode dan multi teknik interpretasi tersebut.

Dalam makalah ini penulis menggunakan metode tahlīliy. Yaitu, dengan menggunakan ilmu syarah hadis naqli atau al-Riwayah dan langkah langkah ' 'aqli atau al-Dirayah. Langkah naqli merupakan syarah al-hadis bi al-Ma'sur, terdiri atas (1) Munasabah al-hadis dengan Alquran, (2) Munasabah al-hadis dengan hadis lainnya, (3) Pandangan sahabat dan tabi'in tentang hadis yang diteliti, (4) Menginventarisir pandangan ulama syarah hadis. Sedangkan dalam langkah 'aql atau bi al-Ra'yi, terdiri atas: (1) Menerjemahkan hadis ke dalam bahasa Indonesia, (2) menerangkan makna kata-kata yang tercantum dalam hadis, (3) Menjelaskan istilah, (4) Menentukan esensi hadis, (5) Menginventarisir nilai-nilai yang terkandung dalam hadis yang diteliti, dan (6) Menganalisa hadis yang disoroti dari berbagai sudut pandang untuk mendapatkan implikasinya terhadap kehidupan.

\section{PEMBAHASAN}

\section{A. Redaksi Lengkap Hadis Halal dan Haram beserta Terjemahnya}

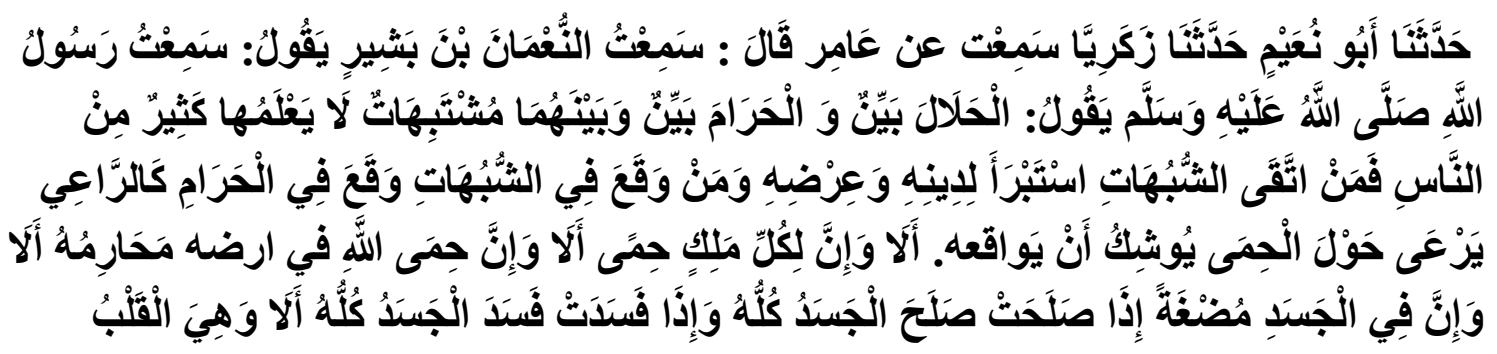

Terjemahnya:

Telah menceritakan kepada kami Abū Nu'aim, telah menceritakan kepada kami Zakaria dari 'Amir berkata; aku mendengar an-Nu'man bin Basyir berkata, aku mendengar Rasulullah saw. bersabda: Yang halal sudah jelas dan yang haram sudah jelas. Namun di antara keduanya ada perkara syubhat (samar) yang tidak diketahui oleh banyak orang. Maka barang siapa yang menjauhi diri dari yang syubhat berarti telah memelihara agamanya dan kehormatannya. Dan barang

${ }^{9}$ Teknik interpretasi teleologis, yakni ayat-ayat Alquran ditafsirkan dengan menggunakan kaidahkaidah fikih yang pada hakikatnya merupakan rumusan dari filsafat hukum Islam yang secara garis besar menghendaki tercapainya kebahagiaan manusia dengan terwujudnya kesejahteraan dan kedamainan. Ibid.

10 Teknik interpretasi kultural, yakni ayat-ayat Alquran ditafsirkan dengan menggunakan pengetahuan yang mapan dan beracu pada asumsi bahwa pengetahuan yang benar tidak bertentangan dengan Alquran. Ibid.

11 Teknik interpretasi logis, yakni ayat-ayat Alquran ditafsirkan dengan menggunakan prinsipprinsip logika dalam memahami kandungan Alquran. Ibid.

12 Teknik interpretasi ganda, yakni ayat-ayat Alquran ditafsirkan dengan mengguna-kan dua atau lebih teknik interpretasi. Ibid., h. 36. 
siapa yang sampai jatuh (mengerjakan) pada perkara-perkara syubhat, sungguh dia seperti seorang penggembala yang menggembalakan ternaknya di pinggir jurang yang dikhawatirkan akan jatuh ke dalamnya. Ketahuilah bahwa setiap raja memiliki batasan, dan ketahuilah bahwa batasan larangan Allah di bumiNya adalah apa-apa yang diharamkan-Nya. Dan ketahuilah pada setiap tubuh ada segumpal darah yang apabila baik maka baiklah tubuh tersebut dan apabila rusak maka rusaklah tubuh tersebut. Ketahuilah, ia adalah hati.

\section{B. Biografi Periwayat Pertama (Sahabat)}

Adapun nama lengkap dari rawi utama ini yaitu, Abu 'Abdullah al-Nu'man bni Basyir bni Sa'ad Tsa'labah bni al-Jalas al-Khazrajiy al-Anshariy. Ibunya adalah 'Amrah Binti Rawayah saudara perempuan dari 'Abdullah bni Rawayah.

Orang tuanya yaitu Basyir bni Sa'ad ikut dalam Perang Badr, ialah yang pertama kali membaiat Abu Bakr al-Siddiq atas kekhalifaannya tahun 13 Hijriyah, ia dilahirkan pada bulan ke-14 pada tahun pertama Hijriyah, ia anak pertama yang dilahirkan dari kaum Anshar sejak kedatangan nabi di Madinah sama seperti 'Abdullah bni al-Zubair sebagai anak pertama dilahirkan dari kaum Muhajirin. Ia terkenal sebagai seorang penyair dan memiliki kumpulan syair.

Nu'man bni Basyir telah diangkat sebagai Gubernur Kufah oleh Mu'awiyah, kemudian pada jaman pemerintahan Yazid ibn Mu'awiyah ia diangkat sebagai Gubernur Damaskus. Sepeninggal Yazid ia ikut membaiat 'Abdullah ibn al-Zubair di Syam dan akhirnya membuahkan pemberontakan dari penduduk Damaskus, akhirnya ia pun melarikan diri dan terbunuh pada Bulan Zulhijjah tahun 64 Hijriyah dalam sumber lain dinyatakan tahun 65 Hijriyah. ${ }^{13}$

\section{Makna Mufradat}

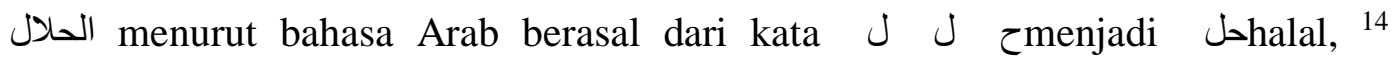
bermaksud berlawanan dengan haram, ${ }^{15}$ ia juga bermakna harus. ${ }^{16}$

Halal adalah suatu istilah ilmu yang berhubungan dengan ketentuan hukum, yaitu sesuatu atau perkara-perkara yang dibolehkan, dianjurkan, bahkan diwajibkan oleh syara'. Sedangkan perkataan haram menurut bahasa Arab berasal dari kata $\rho \tau$ menjadi حرام yaitu berlawanan dengan kata halal, dan al-haram adalam perkara yang diharamkan oleh Allah. ${ }^{17}$

${ }^{13}$ Dikutip dari DR. Sa'ad Sa'ad Jamisy, al-Ma'dabah al-Nabawiah fi al-Hibah, wa al-Washiah wa al-Hadiyah (Mathba'ah al-Quds: al-Mishr, 1980), h. 6-7 dan karim al-Bustani, et al., al-Munjid fii alLugah waa al-I'lam (Cet.33; Beirut: Dar al-Masyriq, 1992) h. 575.

${ }^{14}$ Ibn Manzur, Lisan al- 'Arab (Kairo: Dar al-Ma'arif, t.th.) juz 9, h. 972.

15 Ibid, juz 9, h. 974.

${ }^{16}$ Ahmad Mohtar, Mu'jam al-Luqah al- 'Arabiyah al-Muasirah (Kairo: Alim al-Kutub, 2008) juz 1, h. 548 .

${ }^{17}$ Ibn Manzur, op.cit, juz 9, h. 844-845. 
Yang dimaksud dengan (الْحَمَىى) adalah lahan atau kawasan (khusus) yang subur (yang biasa) dijaga oleh para penguasa (raja). Mereka melarang orang lain untuk mendekatinya. Maka, orang yang mengembalakan hewan-hewan ternaknya, ia sudah sangat dekat dan hampir-hampir memasukinya. Dengan demikian, ia membahayakan dirinya karena akan dihukum.

(مُضْنَةًَ) adalah sepotong daging dengan ukuran yang dapat dikunyah. Dia dinamakan hati karena kebiasaanya yang selalu berubah-rubah. ${ }^{18} \mathrm{Hal}$ ini mengandung penjelasan agungnya kedudukan hati dalam tubuh ini. Sebagaimana juga mengandung penjelasan bahwa hati adalah penguasa seluruh anggota tubuh. Baiknya seluruh anggota tubuh bergantung pada baiknya hati, dan rusaknya anggota tubuh bergantung pada rusaknya hati.

\section{Syarah Hadis}

Ulama sepakat tentang kedudukan yang mulia hadis ini, manfaatnya yang banyak, dan menjadi salah satu hadis inti ajaran Islam.

Salah satu kaedah fiqih yaitu al-aslu fi al-asya'al-ibahah. Yaitu merupakan kaedah pecahan daripada salah satu kaedah utama al-yaqin la yuzal bi al-syak. Dari kaedah tersebut dapat dipahami bahwa setiap sesuatu yang diciptakan Allah adalah halal dan mubah. Tidak ada satu pun yang haram, kecuali ada nas yang jelas yang mengharamkannya. Sekiranya tidak ada nas yang jelas, seperti Alquran dan Hadis yang menunjukkan keharamannya, maka perkara tersebut adalah mubah.

Perbuatan manusia dalam kehidupan tidak terlepas antara halal dan haram, antara kebajikan dan maksiat. Allah Swt., tidak menghalalkan suatu perkara kepada manusia kecuali ada kebaikan dalam perkara tersebut dan Allah tidak akan mengharamkan sesuatu jika tidak akan mendatangkan mudharat bagi manusia.

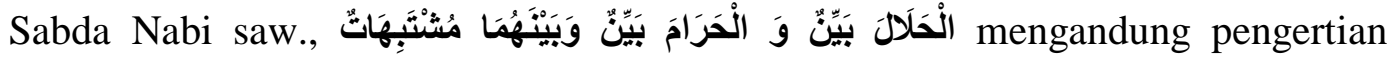
bahwa segala sesuatu itu terbagi menjadi tiga:

Pertama: Sesuatu yang jelas halalnya, seperti; biji-bijian, buah-buahan, hewanhewan ternak. Itu semua halal jika tidak didapatkan dari cara yang haram.

Kedua: Sesuatu yang jelas haramnya, seperti daging babi, meminum khamr (minuman keras memabukkan), memakan bangkai, menikahi wanita-wanita yang mahram.

Ketiga: Perkara-perkara syubhat (samar) yang berkisar antara yang halal dan haram. Ia bukan termasuk hal-hal yang jelas halalnya, dan bukan pula termasuk hal-hal yang jelas haramnya. Hal-hal inilah yang tidak diketahui oleh kebanyakan orang. Namun, hanya diketahui oleh sebagian mereka.

الْحَلَلَ بَيِّنُ وَ الْحَرَامَ (yang halal jelas dan yang haram jelas), yaitu dalam dzat dan sifatnya sesuai dalil yang zhahir.

${ }^{18}$ Ahmad ibn Ali ibn Hajar al-Asqalaniy, Fath al-Bariy Sarah Shahih al-Bukhariy (Cet. II;Beirut: Dar al-Kutub al-Alamiyah, 1997) juz 1, h. 171. 
وَبَيْنَهُمَا مُشْنَتِهَهَاتُ (dan dianatara keduanya adalah hal yang meragukan ), artinya halhal yang tersamarkan yang tidak diketahui hukumnya secara pasti. Dalam riwayat Al

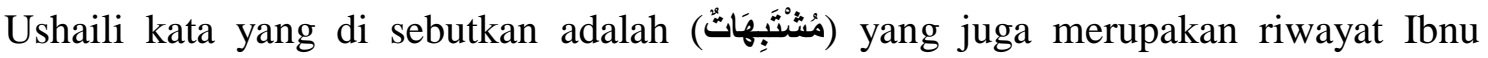
Majah dengan Lafazh Ibnu 'Aun. Maknanya, keduanya sepakat untuk memperoleh hal yang serupa dari dua sisi yang saling bertolak belakang. Kemudian diriwayatkan oleh Ad-Darimi dari Abi Nu'aim, Syaikh Imam Bukhari dengan lafazh (مُتشَابَهََاتُ "Dan diantara keduanya terdapat perkara yang diragukan."

Syubhat di sini ialah sesuatu yang masih dipertentangkan hukumnya berdasarkan dalil-dalil yang ada dalam Kitab dan Sunnah, dan maknanya pun masih diperdebatkan.

Sebagian ulama berpendapat bahwa syubhat ialah perkara haram. Mereka berargumen berdasarkan sabda Nabi tersebut, ".......berarti dia telah menyelamatkan agama dan kehormatannya......" Barang siapa yang tidak membersihkan agama dan kehormatannya, ia terjerumus dalam perkara yang diharamkan.

Sebagian ulama berpendapat bahwa perkara syubhat adalah sesuatu yang halal. Dasar mereka adalah sabda Beliau, “......sebagaimana penggembala yang menggembalakan hewan gembalaannya di sekitar (ladang) yang dilarang untuk memasukinya....." Kalimat ini menunjukan bahwa syubhat adalah sesuatu yang halal, dan meninggalkannya adalah perbuatan wara'.

Ulama lain berpendapat bahwa syubhat bukanlah sesuatu yang halal atau sesuatu yang haram. Pasalnya, Nabi secara jelas memposisikan perkara syubhat di antara yang halal dan yang haram. Hanya saja, sebagai langkah kehati-hatian, seyogyanya kita menghindari barang syubhat. Tindakan seperti ini juga bagian dari sikap wara'.

Kita harus menjauhi sesuatu yang syubhat, karena siapa yang terjerumus dalam perkara syubhat, maka lambat laun ia pasti akan terjerembab perkara yang haram. Sebagaimana dikatakan, "kemaksiatan adalah kurir kekufuran".

لَا يَعْلَمُها كَثَيْرٌ مِنْ النَّاس "(tidak banyak orang yang mengetahui). Maksudnya adalah tidak diketahui hukumnya oleh sebagian besar manusia, kecuali hanya sebagian kecil dari manusia, yaitu para Mujtahid. ${ }^{19}$

Hal tersebut dijelaskan dalam riwayat At-Tirmidzi dengan lafazh, "banyak orang yang tidak mengetahui apakah perkara tersebut halal atau haram." Yang dapat dipahami dari kata (كَثَرْ (كَ) adalah bahwa yang mengetahui hukum perkara tersebut hanya sebagaian kecil manusia, yaitu para mujtahid, sehingga orang yang ragu-ragu adalah selain mereka. Namun terkadang syubhat itu ada dalam diri para mujtahid, jika mereka tidak dapat mentarjih (menguatkan) salah satu diantara dua dalil.

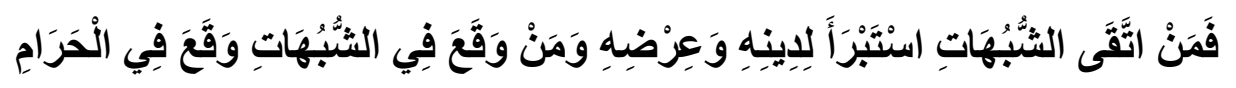

Maka barang siapa yang menjauhi diri dari yang syubhat berarti telah memelihara agamanya dan kehormatannya. Dan barang siapa yang sampai jatuh (mengerjakan) pada perkara-perkara syubhat, maka ia telah mengerjakan yang haram.

\footnotetext{
${ }^{19}$ Ibid. juz 1, h. 169.
} 
Maksudnya adalah barang siapa yang berhati-hati atau menjaga dirinya dari perkara syubhat, maka agamanya telah terbebas dari kekurangan, dan Karena pada hal demikian ini terdapat keselamatan bagi agamanya yang urusannya berkaitan antara dia dan Allah. Juga terdapat keselamatan bagi kehormatannya yang hubungannya antara dia dan orang lain. Sehingga, dengan demikian, tidak ada lagi celah dan kesempatan bagi orang lain untuk mencelanya.

Namun, jika ia menganggap remeh perkara-perkara syubhat ini, ia pun mungkin akan terjerumus ke dalam perbuatan yang jelas keharamannya.

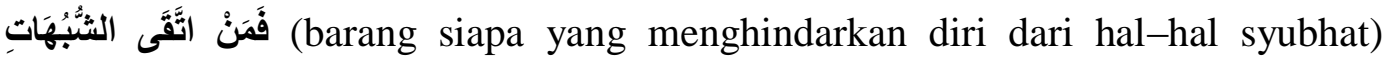
artinya berhati-hati dengan perkara yang syubhat. Perbedaan antara para perawi dalam lafazh hadits, adalah seperti sebelumnya. Tapi menurut Muslim dan Ismaili adalah

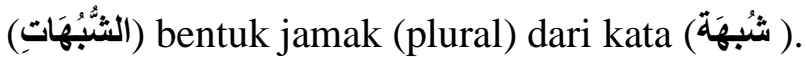

(اسْنَبْرَاً) Maksudnya adalah menjaga kesucian agamanya, dan menjaga kehormatannya dari pembicaraan orang lain. Agamanya selamat dari kekurangan dan perilakunya, selamat dari celaan, karena orang yang tidak menghindari hal-hal syubhat, maka dia tidak akan selamat dari perkataan orang yang mencelanya.

Hadits ini menjelaskan, bahwa orang yang tidak menjauhkan diri dari syubhat dalam pencaharian dan kehidupannya, maka dia telah menyerahkan dirinya untuk dicemooh dan dicela. Hal ini mengandung petunjuk untuk selalu menjaga hal-hal yang berkaitan dengan agama dan kemanusiaan.

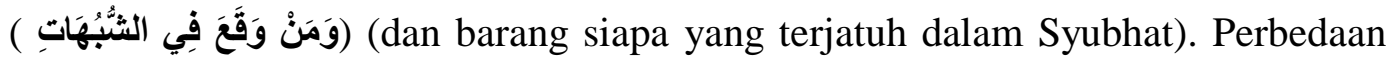
para perawi dalam kalimat ini seperti yang telah dikemukakan. Disamping itu para ulama juga berselisih tentang hukum syubhat, ada yang mengatakan haram dan ada yang mengatakan makruh. Kasus ini sama dengan perbedaan pendapat tentang hukum sebelum turunya syariat. Ringkasnya, ada empat penafsiran tentang syubhat. Yaitu,

1. Terjadi pertentangan dalil-dalil yang ada, seperti disebutkan diatas.

2. Perbedaan ulama yang bermula dari adanya dalil-dalil yang saling bertentangan.

3. Yang dimaksud dengan kata tersebut (syubhat) adalah yang disebut dengan makruh, karena kata tersebut mengandung unsur "melakukan" dan "meninggalkan".

4. Yang diamksud dengan syubhat adalah mubah (yang diperbolehkan).

Tidak diragukan lagi bahwa orang yang banyak melakukan sesuatu yang makruh, akan berani melakukan sesuatu yang haram, atau kebiasaannya melakukan sesuatu yang tidak diharamkan tersebut menyebabkannya melakukan sesuatu yang diharamkan, atau dikarenakan ada syubhat didalamnya sehingga orang yang mengerjakan sesuatu yang dilarang, hatinya akan gelap kerena kehilangan sifat wara' (kehati-hatian) dalam dirinya, dimana hal tersebut akan menyebabkan jatuh kedalam hal yang haram.

( كَالََّاعِي يَرْغَىَ) (seperti penggembala yang menggembalakan). Demikianlah yang ditemukan dalam setiap teks imam Bukhari dengan dihapuskannya jawab syarth apabila kata (مَنْ) (orang) yang dianggap berfungsi sebagai syarth. Penghapusan tersebut juga 
dikuatkan dalam riwayat Ad Darimi dari Abu Nu'aim Syaikh Imam Bukhari. Dalam

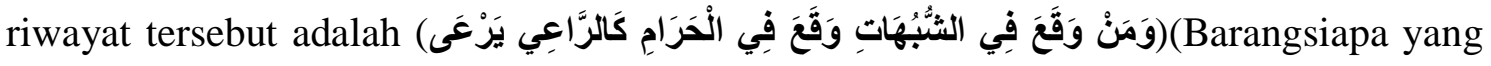
melakukan sesuatu yang diragukan maka dia terjatuh ke dalam yang haram seperti penggembala yang menggembalakan).

Akan tetapi kata (مَنْ) dalam lafazh Bukhari dapat pula dianggap sebagai man maushulah (sambung). Dengan demikian maka tidak ada penghapusan di dalamnya, sehingga artinya menjadi, "barangsiapa yang melakukan sesuatu yang meragukan maka orang tersebut seperti penggembala yang menggembalakan ternaknya".

Pendapat pertama lebih utama untuk diterima, karena penghapusan tersebut diperkuat dengan riwayat Muslim dan yang lainnya dari jalur Zakaria yang juga merupakan riwayat Imam Bukhari. Berdasarkan hal ini, maka perkataanya, كَالرَّاعِي يَرْغَى berfungsi sebagai kata awal untuk menarik perhatian terhadap sesuatu yang belum terjadi dengan sesuatu yang ada.

Sungguh Nabi saw. telah memberikan sebuah perumpamaan hal itu bagaikan seorang penggembala yang menggembalakan hewan ternaknya di sekitar kawasan terlarang.

Maka apabila ia jauh dari kawasan terlarang tersebut, ia pun akan selamat dalam menggembalakan hewan-hewan ternaknya. Namun, jika ia dekat-dekat dengan kawasan terlarang tersebut, dikhawatirkan akan dimasukinya kawasan tersebut berserta hewanhewan ternaknya, sedangkan ia tidak menyadarinya. Barangsiapa terjerumus ke dalam syubhat, ia pun terjerumus ke dalam (hal-hal yang) haram. Ini mengandung dua makna/perkara:

Pertama: Ia terjerumus ke dalam keharaman, namun ia mengira bahwa hal itu tidak haram.

Kedua: Ia mendekati (hampir-hampir) terjerumus ke dalam keharaman. Dan hal ini seperti perkataan (المِعَاصِي بَرِيُْ الْكَفْرِ) "Maksiat-maksiat mengantarkan kepada kekafiran.”. Karena seseorang, jika terjatuh kepada perbuatan menyimpang (maksiat), ia akan bertahap dan berpindah kepada kerusakan (maksiat) yang lebih besar dari yang semula.

(Ketahuilah, sesungguhnya setiap penguasa (raja) memiliki kawasan terlarang. Ketahuilah, sesungguhnya kawasan terlarang Allah adalah hal-hal yang diharamkan-Nya)." Ini kembalinya kepada bagian yang ketiga, yaitu perkara-perkara syubhat. Maka, hendaknya seseorang menjauhinya. Sedangkan, kawasan terlarang Allah adalah hal-hal yang diharamkan-Nya. Maka wajib bagi setiap orang untuk menjauhinya. Sehingga, ia pun wajib menjauhi perkara-perkara syubhat yang bisa mengantarkannya kepada perbuatan haram.

Raja baik di tanah Arab atau selainnya, memiliki sesuatu yang dilindungi orang lain, dan melarang manusia untuk memasukinya. Barangsiapa memasukinya maka akan mendapatkan hukuman, dan barang siapa menjaga dirinya, pasti tidak mendekati sesuatu yang dilindungi tersebut, agar tidak mendapatkan hukuman. Begitu juga Allah 
Swt. Ada sesuatu yang dilindungi-Nya. Yaitu, sesuatu yang haram atau perbuatanperbuatan yang diharamkan Allah Swt. Seperti; membunuh, zina, mencuri, arak, bohong, gibah, namimah, memakan yang bukan haknya, dan lain sebagainya. Kesemuanya itu dilindungi Allah Swt. agar manusia tidak memasukinya. Barang siapa memasuki yang dilindungi Allah, dengan cara mengerjakan larangan tersebut, maka dia berhak mendapat hukuman, dan barang siapa mendekatinya, kemungkinan akan terperosok, dan siapa yang menjaga dirinya, pasti tidak akan mendekatinya. Agar tidak mendekati maksiat, maka dimulai dengan meninggalkan yang subhat.

Dalam riwayat Mustamli tidak menggunakan kalimat في ارضه Sedangkan dalam riwayat selain Abu Dzarr, huruf "waw” dicantumkan dalam kalimat أَلَا وَإِنَّ حِمَى اللَّهِ (dan sesungguhnya larangan Allah). Yang dimaksud dengan مَحَارِمُ adalah perbuatan yang diharamkan, atau meninggalkan pekerjaan yang wajib, maka dalam riwayat Abi Farwah diinterpretasikan dengan معاصي (kemaksiatan). Sebagai ganti dari مَحَارِمُ (yang diharamkan). Sedangkan kata أَّي berfungsi memperingatkan bahwa setelahnya adalah kebenaran.

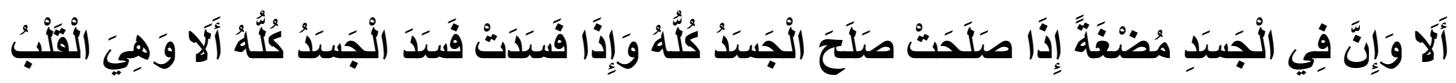

(Dan ketahuilah pada setiap tubuh ada segumpal darah yang apabila baik maka baiklah tubuh tersebut dan apabila rusak maka rusaklah tubuh tersebut. Ketahuilah, ia adalah hati).

Hati bagaikan raja yang menggerakkan tubuh untuk melakukan perbuatanperbuatannya, jika hati tersebut adalah hati yang baik, maka seluruh tubuhnya akan tergerak untuk mengerjakan hal-hal yang baik. Sebaliknya jika hatinya adalah hati yang buruk, maka tentunya juga akan membawa tubuh melakukan hal-hal yang buruk.

dinamakan hati, karena sifatnya yang selalu berubah, atau karena dia adalah bagian badan yang paling bersih, atau karena dia diletakkan secara terbalik di dalam badan.

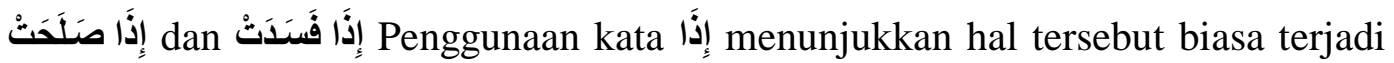
dan bias juga berarti "jika" seperti yang ada di riwayat ini. Dikhususkan hati dalam hal ini, karena hati adalah pemimpin badan. Jika pemimpinnya baik, maka rakyat pun akan baik, demikian pula sebaliknya.

Hadis ini mengandung peringatan akan pentingnya hati, dorongan untuk memperbaikinya, dan isyarat bahwa nafkah yang baik memiliki efek terhadap hati, yaitu pemahaman yang diberikan oleh Allah.

\section{KESIMPULAN}

Dari uraian hadis yang telah disampaikan dapat ditarik kesimpulan bahwa:

1. Syariat Islam, halalnya jelas dan haramnya jelas pula. Sementara yang samar (syubhat) darinya diketahui oleh sebagian orang tentang hukum dan dalilnya. 
2. Ketika suatu perkara tidak jelas bagi manusia; apakah halal atau haram, maka seyogyanya dijauhi hingga menjadi jelas baginya bahwa perkara tersebut adalah halal.

3. Berhati-hati (dan menjuhi diri) dari perkara-perkara syubhat merupakan penjagaan diri terhadap agama seseorang dari kekurangan, dan penjagaan terhadap harga dirinya dari celaan-celaan.

4. Sesungguhnya seseorang, jika ia terjatuh ke dalam perkara syubhat, ia akan mudah meremehkan perkara-perkara yang jelas (haramnya).

5. Rasulullah saw., mendidik dengan baik, dengan cara membuat berbagai perumpamaan dan menjelasakannya.

6. Poros kebaikan dan kerusakan terletak pada hati. Maka wajib bagi manusia menjaga hatinya agar tetap terpelihara dari perkara-perkara yang bisa merusaknya.

7. Kerusakan zahir adalah tanda kerusakan batin.

\section{DAFTAR PUSTAKA}

Al-Qur'ān al-Karìm

Dahlan, Abdul Aziz. (ed.), Ensiklopedia Hukum Islam, jilid III. Cet. I; Jakarta: Ichtiar Baru Van Houve, 1997

Al-Farmāwy, Abd. al-Hayy. al-Bidāyat fi al-tafsìr al-Mawdū'iy, diterjemahkan oleh Siryan A. Jamrah dengan judul Metode Tafsir Mawdhu'iy. Cet. I; Jakarta: LSIK dan PT. Raja Grafindo Persada, 1994

Ibn al-Shalāh, Abū Amar 'Uśmān bin 'Abd. al-Rahmān. 'Ulūm al-Hadīś, naskah diteliti oleh Nūr al-Dīn 'Itr. Madīnah: Maktab al-Madīnah al-Munawwar, 1972

Ibn Futuh, Muhammad. Taqrīrāt al-Saniyah min 'Ilm al-Hadīś. Bandung: Syirkah Nūr Asia, t.th

al-Hadi, Abu Muhammad Mahdi 'Abd al-Qadir ibn 'Abdullah. Turuq Takhrij Hadis Rasulillah saw. terj. Said Aqil Husain Munawwar dan Ahmad Rifqi Mukhtar. Metode Takhrij Hadis.Cet. I; Semarang: Dina Utama, 1994

Al-Nawawiy, Abū Zakariyah Yahya bin Syaraf. Shahīh Muslim bi Syarh al-Nawawiy, ditahqiq oleh 'Ādil 'Abd. al-Mawjūd dan 'Ali Ma'awd, Cet. II; Riyād: Maktabah Nizār Mushthāfa al-Bāriz, t.th dan terbitan Dār al-Fikr.

Khalifah, Muhammad Rasad. Taujihat min as-sunnah fi Majal al-Akhlaq wa al-Usrah. (Cet. III; Kairo: Matbaah al-Madani, 1988

Ismail, M. Syuhudi. Metodologi Penelitian Hadis Nabi. Cet. I; Jakarta: Bulan Bintang, 1992

Sabiq, Sayyid. Fiqh al-Sunnah, juz IV. Mesir: Musthāfa al-Bāb al-Halab, 1989 
Al-Sālih, Subhi. 'Ulūm al-Hadīś wa Mushthalahuhu. Bairūt: Dār 'Ilm al-Malāyīn, 1977

Salim, H. Abd. Muin. Fiqh Siyasah; Konsepsi Kekuasaan Politik dalam Al-Quran. Cet. I; Jakarta: RajaGrafindo Persada, 1994

Al-Shan'āniy, al-Sayyid al-Imam Muhammad bin Ismā'il al-Kahlāni. Subul al-Salām, Barūt: Dār al-Fikr, t.th

Tim Penyusun IAIN Syarif Hidayatullah, Ensiklopedi Islam. Jakarta: Djambatan, 1992

Tim Penyusun Kamus Pusat Pembinaan dan Pengembangan Bahasa, Kamus Besar Bahasa Indonesia, edisi II. Cet.IV; Jakarta: Balai Pustaka, 1995 